\title{
Prevalence of $C$, botulinum and $C$. perfringens spores in food products available on Polish market
}

\author{
Tomasz Grenda ${ }^{1}$, Magdalena Grabczak ${ }^{1}$, Krzysztof Kwiatek ${ }^{1}$, Andrzej Bober ${ }^{2}$ \\ ${ }^{1}$ Department of Hygiene of Animal Feedingstuffs \\ ${ }^{2}$ Department of Honey Bee Diseases \\ National Veterinary Research Institute, 24-100 Pulawy, Poland \\ tomasz.grenda@piwet.pulawy.pl
}

Received: April 3, 2017

Accepted: August 25, 2017

\begin{abstract}
Introduction: The aim of this study was to evaluate the prevalence of Clostridium botulinum and Clostridium perfringens in food samples purchased from Polish producers. Material and Methods: The analyses were performed on 260 food samples collected in Lublin and Subcarpathian regions: 56 of smoked meat, 21 of pork meat, 20 of dairy products, 26 of vegetable and fruit preserves, 40 of ready-to-eat meals, 27 of fish preserves, and 70 of honey collected directly from apiaries. Results: C. botulinum strains were isolated from $2.3 \%(6 / 260)$ of samples and the isolates were classified as toxin types A (4/260) and B (2/260). C. perfringens strains were isolated from 14\% (37/260) of samples. All the isolates were classified as toxin type A, 28 of them were able also to produce $\alpha$ toxin and $9-\beta 2$ toxin. Conclusion: On the basis of the obtained results it could be suggested that risk assessment, especially regarding the entire honey harvesting process, should be provided in order to ensure the microbiological safety of the products to be consumed by infants and people with a weakened immune system.
\end{abstract}

Keywords: food, Clostridium botulinum, Clostridium perfringens, Poland.

\section{Introduction}

Clostridium is a genus of Gram positive, sporeforming bacteria, which are able to grow under anaerobic conditions. Generally, the majority of these bacterial species are considered as saprophytic; however, some of them could cause severe health failures to the host organism $(1,3,9,23)$.

Spore-forming, anaerobic rods, which are able to produce botulinum toxins, are classified as the C. botulinum species. However, other species belonging to the genus Clostridium, such as $C$. argentinense (reported in literature as C. botulinum type G) and some strains of C. baratii and C. butyricum, can produce these toxins. The toxins are considered as the most dangerous biological substances in the environment $(1,9,10)$.

Botulism is caused by immunologically distinct toxins (types A-G, and potentially $\mathrm{H}$; data on the latter toxin type are under verification $(3,6)$ ), produced by C. botulinum, or rarely C. butyricum (E) or C. baratii (F) $(1,4,9,10)$. Human botulism cases are caused mainly by A, B, and $\mathrm{E}$ toxin types. Five clinical forms of human botulism are recognised. Three of them are associated with consumption of food contaminated with toxins or C. botulinum spores. The most frequent form is classic or foodborne botulism and it represents a typical form of intoxication, where botulinum toxin is ingested and transported through blood to the synapses of neurons. Infant botulism is characterised by ingestion, multiplication, and colonisation of C. botulinum spores in the intestinal tract. Intestinal microbiota and composition of bile acids of infant's digestive tract do not represent a sufficient biological barrier to inhibit the multiplication and colonisation with $C$. botulinum (4); $15 \%$ of cases are associated with the presence of honey in infants' nutrition (19). Another form of intoxication is hidden botulism, with the symptoms of this form similar to infant botulism. It is also determined as adult variant of infant form and is caused by abnormalities of the digestive tract of adults, possibly due to previous antibiotic therapy or gastroenterological surgery (4).

The lethal dose of botulinum toxin for humans ranges from $0.2 \mu \mathrm{g} / \mathrm{kg}$ to $2 \mu \mathrm{g} / \mathrm{kg}$ of body weight (24), 
but the exact infective number of $C$. botulinum spores is unknown.

Clostridium perfringens is a Gram-positive, sporeforming, anaerobic bacterium residing in soil, water, and gastrointestinal tract of various animals and humans. This ubiquitous microorganism is able to produce more than 15 different protein toxins with diverse modes of action. Five toxin types of this bacteria are distinguished, from $\mathrm{A}$ to $\mathrm{E}$, on the basis of its ability to produce one or combination of four main toxins which are marked $\alpha, \beta, \varepsilon$, and $\mathrm{l}(7)$. The majority of human infections are caused by type A, despite the fact that this toxin type is considered an opportunistic pathogen, usually found as a natural saprophytic inhabitant of native microbiota of humans and animals. Occurrence of B, C, D, and E toxin types is always connected with disease symptoms. Clostridium perfringens could be transferred to food with soil, dust, through intestinal tract of slaughtered animals, and contamination due to inadequate hygiene during technological processing in abattoirs. In humans, it could cause diarrhoea and abdominal cramps within $24 \mathrm{~h}$. The illness usually begins suddenly and lasts for less than $24 \mathrm{~h}$. People infected with $C$. perfringens usually do not show fever or vomiting. The infection does not spread from person to person $(2,7)$.

The aim of this study was to evaluate the prevalence of $C$. botulinum and $C$. perfringens in food samples purchased from Polish producers. The samples of the products were analysed with a traditional culturing method, mouse bioassay, and molecular biology methods based on real-time PCR, PCR, and sequence analysis of PCR products.

\section{Material and Methods}

Positive controls. The following $C$. botulinum reference strains from NTCT collection were used as positive controls: NCTC 887 (type A), NCTC 3815 (type B), NCTC 8548 (type C), NCTC 8265 (type D), NCTC 8266 (type E), NCTC 10281 (type F) and C. perfringens strains: ATCC 13124 (type A able to produce toxin $\alpha$ ) and A544/84 (isolate type A from the collection of the Department of Hygiene of Animal Feedingstuffs, able to produce toxins $\alpha$ and $\beta 2$ ).

Samples. The analyses were carried out on 260 food samples: 56 of smoked meat, 21 of pork meat, 20 of dairy products, 26 of vegetable and fruit preserves, 40 of ready-to-eat meals, 27 of fish preserves, and 70 of honey collected directly from apiaries. The samples were collected in Lublin and Subcarpathian regions in 2011-2015. All products selected for the experiment were purchased from Polish producers.

Inoculation and culturing. Each sample (10 g) was inoculated directly to TPGY broth. Subsequently, inocula were subjected to pasteurisation process and incubated under anaerobic conditions for $72 \mathrm{~h}$ at $30^{\circ} \mathrm{C}$.
Anaerobic conditions were obtained using Oxoid system (Thermo Scientific, UK). Subsequently, 2-3 drops of liquid culture were inoculated onto the surface of Willis-Hobbs agar and incubated at $30^{\circ} \mathrm{C}$ for $48 \mathrm{~h}$. After incubation on Willis-Hobbs agar, the phenotypic features characteristic for C. botulinum and C. perfringens were evaluated according to the protocol described in PN-R-64791:1994 (21). At the same time, $1 \mathrm{~mL}$ of liquid culture was transferred into tube with fresh TPGY broth, and incubated for $18 \mathrm{~h}$ at $30^{\circ} \mathrm{C}$ under anaerobic conditions. After incubation, the obtained culture was subjected to DNA extraction.

Extraction of DNA. The DNA was extracted from liquid culture and suspected colonies with the use of GenomicMini AX Bacteria commercial kit (A\&A Biotechnology, Poland) according to the protocol described by the producer.

PCR methods. The real-time PCR screening method was used for $C$. botulinum detection, based on ntnh gene detection according to Raphael et al. (22) with modifications by Grenda et al. (8). Real-time PCR results were verified using multiplex PCR method for detection of specific BoNT genes determining production of $\mathrm{A}, \mathrm{B}, \mathrm{E}$, and $\mathrm{F}$ toxins according to De Medici et al. (5). All PCR methods used in this study were previously validated on artificially contaminated food and feed matrices (8).

Sequence analysis. Because of difficulties with isolation and discrimination of $C$. botulinum, positive results of PCR were confirmed by sequencing. The analysis was performed with the same set of primers which was used in multiplex PCR. The obtained results of sequencing were analysed with the BLAST (Basic Local Aligment Search Tool) algorithm in order to detect the homology of PCR product sequences with those from GenBank (http://blast.ncbi.nlm.nih.gov/ Blast.cgi).

DNA extraction for $C$. perfringens detection. DNA extraction from the strains suspected of belonging to $C$. perfringens species was conducted according to the protocol described by Baums et al. (2).

Multiplex PCR method. Detection and determination of $C$. perfringens toxin types were conducted according to the method described by Baums et al. (2). This method enables detection of cpa, $c p b$, cpe, and cpi genes determining the production of main toxins: $\alpha, \beta, \varepsilon$, and 1 , and $c p b 2$ and cpe genes determining the production of additional toxins: $\beta 2$ and CPE.

Gel electrophoresis. Gel electrophoresis was conducted in $2 \%$ agarose gel stained with ethidium bromide and run in $1 \times$ TBE buffer (Fermentas, Lithuania) for $1.5 \mathrm{~h}$ under $100 \mathrm{~V}$. Reaction mixture in a $10 \mu \mathrm{L}$ volume and $2 \mu \mathrm{L}$ of loading buffer $6 \times$ DNA Loading Dye (Fermentas, Lithuania) was loaded into each well. The molecular weight of the obtained products was compared with a molecular weight marker - GeneRuler ${ }^{\mathrm{TM}} 100$ bp DNA Ladder Mix 
(Fermentas, Lithuania). PCR products were analysed under a UV light transluminator (Vilbe-Lourmat, France).

Mouse bioassay. This test was performed for isolates suspected of $C$. botulinum occurrence. The single experiment was carried out on three laboratory mice, following FDA protocol (1). TPGY cultures of suspected strains were centrifuged and the supernatant was divided into three $0.2 \mathrm{~mL}$ portions. One of them was heated at $100^{\circ} \mathrm{C}$ for $10 \mathrm{~min}$ and administered intraperitoneally to one mouse. The other two were administered intraperitoneally to two other mice, one of which had previously been seroneutralised by equine monovalent antitoxin to botulinum neurotoxins A (BoNT/A) and B (BoNT/B) (HPA, UK).

Biochemical tests. The biochemical properties of suspected strains were evaluated with API 20A and Rapid ID 32A tests for anaerobic bacteria. The analyses were performed according to the producer's protocol.

\section{Results}

C. botulinum strains were isolated from $2.3 \%$ $(6 / 260)$ of samples and the isolates were classified as toxin types A (4/260) and B (2/260). Positive results were only observed for honey samples and their number equalled $8.5 \%(6 / 70)$. Only proteolytic C. botulinum strains were isolated (Table 1). Also, the number of strains phenotypically similar to $C$. botulinum species ( $C$. botulinum-like strains) was the highest for this matrix. The exact discrimination among Clostridium strains was not possible with API $20 \mathrm{~A}$ test. This test failed to differentiate strains of metabolic group I to which proteolytic strains of $C$. botulinum and $C$. sporogenes are classified. Suspected strains were classified as C. botulinum/ C. sporogenes. Strains phenotypically similar to C. botulinum species were classified to $C$. botulinum
(2/8) and to $C$. sporogenes (6/8) according to the Rapid ID $32 \mathrm{~A}$ test. Both the latter and API 20A tests are invalid in $C$. botulinum detection. The sequencing of PCR products characteristic for $C$. botulinum species showed high level of homology to BoNT sequences deposited in GenBank. Mouse bioassay confirmed all positive results obtained from PCR analyses for C. botulinum species (Table 2). Example of positive PCR results for $C$. botulinum type B isolates is shown in Fig. 1.

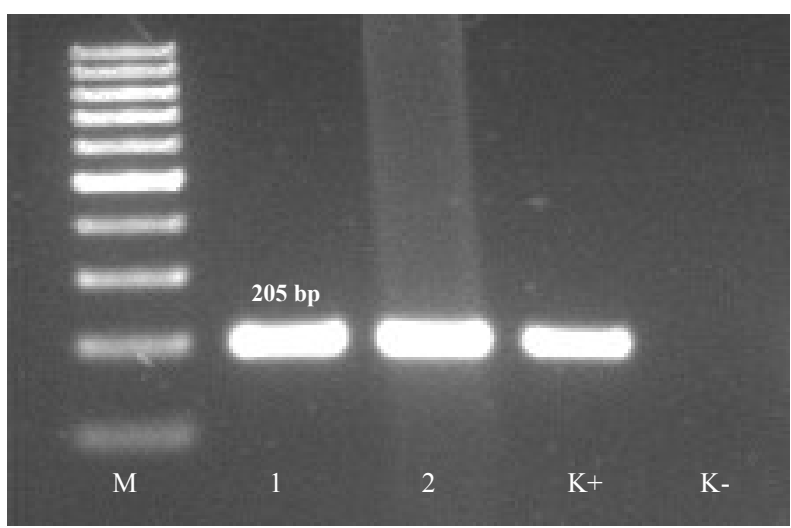

Fig. 1. Example of positive PCR products characteristic for C. botulinum toxin type B (205 bp).

M - molecular mass marker; 1, 2 - products characteristic for C. botulinum type B (205 bp); $\mathrm{K}+-$ positive control (DNA from C. botulinum NCTC 3815 able to produce BoNT/B); K- - negative control

C. perfringens strains were isolated from $14 \%$ $(37 / 260)$ of examined samples. All isolates were classified as toxin type A; additionally, 28 of them were able to produce $\alpha$ and $9-\beta 2$ toxins (Table 1). According to the results of API 20A and Rapid ID 32A tests, all isolates were classified as $C$. perfringens species. An example of positive PCR results for C. perfringens type A isolates is shown in Fig. 2.

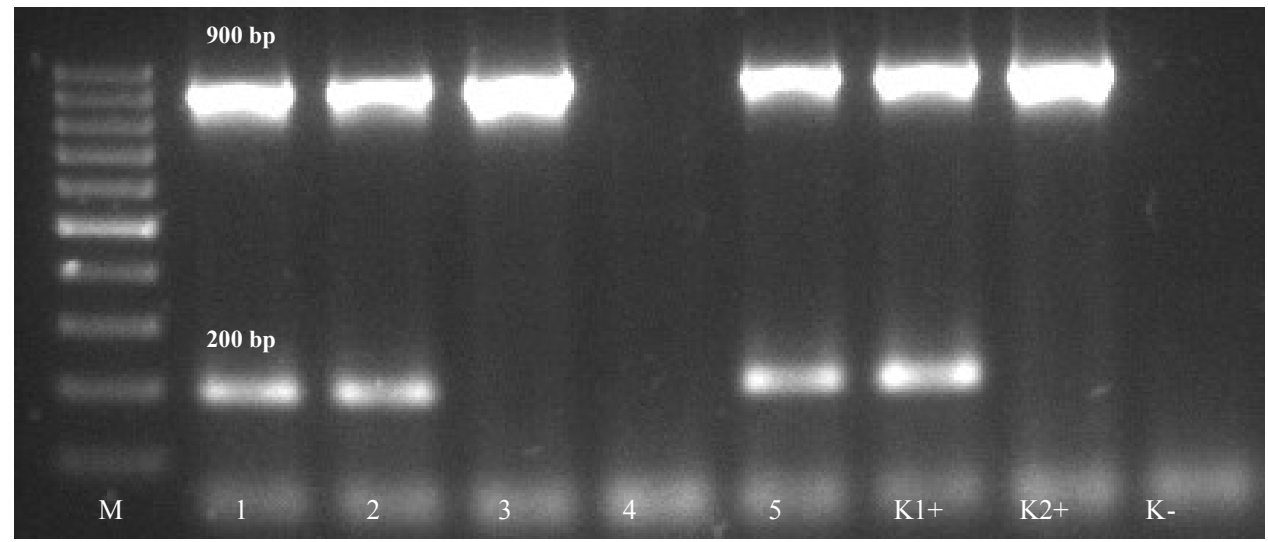

Fig. 2. Example of positive PCR products characteristic for $C$. perfringens type A able to produce toxins $\alpha$ (900 bp) and $\beta 2(200 \mathrm{bp})$.

$\mathrm{M}$ - molecular mass marker; 1, 2, 5- products characteristic for $C$. perfringens type A able to produce toxins $\alpha$ and $\beta 2 ; 3$-product characteristic for $C$. perfringens type A able to produce toxin $\alpha ; \mathrm{K} 1+-$ positive control (DNA from $C$. perfringens A544/84 able to produce toxins $\alpha$ and $\beta 2$ ) K2+ - positive control (DNA from C. perfringens ATCC 13124 able to produce toxin $\alpha$ ); K- - negative control 
Table 1. Occurrence of Clostridium strains in examined food samples

\begin{tabular}{lllll}
\hline Sample & Number of samples & C.perfringens & C. botulinum & C. botulinum-like strains \\
\hline Smoked meat & 56 & - & - & - \\
\hline Meat & 21 & 4 & - & - \\
\hline Dairy products & 20 & - & - & - \\
\hline $\begin{array}{l}\text { Vegetable and fruit } \\
\text { preserves }\end{array}$ & 26 & 2 & - & - \\
\hline Ready-to-eat meals & 40 & 4 & - & 1 \\
\hline Fish preserves & 27 & 1 & - & - \\
\hline Honey & 70 & 26 & $4 \mathrm{~A}, 2 \mathrm{~B}$ & 7 \\
\hline Total & 260 & $37(14 \%)$ & $6(2.3 \%)$ & $8(3 \%)$ \\
\hline
\end{tabular}

Table 2. Homology of PCR products characteristic for C. botulinum isolates type A and $\mathrm{B}$ to sequences from GenBank

\begin{tabular}{lll}
\hline Strain number & Homology $(\%)$ & GenBank number of homologous sequences \\
\hline APH1 & $92 \%$ & FJ981688 \\
\hline APH2 & $85 \%$ & FJ981688 \\
\hline APH3 & $88 \%$ & EU341306 \\
\hline APH4 & $97 \%$ & FJ981688 \\
\hline BPH1 & $93 \%$ & NC_012654 \\
\hline BPH2 & $95 \%$ & NC_012654 \\
\hline
\end{tabular}

APH1; APH2; APH3, APH4 - toxin type A; BPH1; BPH2 - toxin type B

\section{Discussion}

Botulism cases in Poland have been reported since 1952. The frequency of the disease was very high in the $1960 \mathrm{~s}$ and 1970s (e.g. in 1964 - 201 cases were reported), as well as in the $1980 \mathrm{~s}$, when due to the politically driven food crisis the production of homemade preserves was popular, albeit not always under sufficiently hygienic conditions. For example, in 1982 - 784 cases were reported in Poland, whereas the reports from other European countries showed a significantly lower number of botulism cases: Italy 412 cases, Germany - 177, Spain - 92 (12). Nowadays, according to the reports of the National Institute of Public Health - National Institute of Hygiene, approximately 30 botulism cases are reported in Poland annually (29 cases in 2014 and 29 in 2015) (http:// wwwold.pzh.gov.pl/oldpage/epimeld/index_p.html).

The natural contamination level of food products with $C$. botulinum spores is generally low and ranges from 10 to 1,000 spores/g (14). The obtained results showed difficulties in C. botulinum detection caused by low level of contamination, which could be higher than the limit of detection of methods used in the experiment and by the isolation of non-toxigenic strains or high contamination level, especially of honey samples by the other Clostridium strains. The location of neurotoxin genes cluster on plasmids and the loss of toxigenic properties during the culturing process are possible (4). This limitation was clearly visible for the isolates which have shown the biochemical features characteristic for $C$. botulinum strains. Biochemical tests are not sufficient for differentiation between
C. botulinum and suspected strains belonging to this species. The high occurrence of $C$. perfringens could cause the inhibitory effect in C. botulinum isolation and detection, because of faster growth and lower nutritional demands of the first one. Combase model (http://www.combase.cc) shows that the number of C. perfringens can double during approximately $50 \mathrm{~min}$ at $30^{\circ} \mathrm{C}(\mathrm{pH} \mathrm{5}$, aw $=0.997)$, whilst the number of C. botulinum cells does the same after approximately 154 min. Furthermore, the results of biochemical testing seem to correlate with the results described by Linström et al. (13) who noticed that C. botulinum and botulinum-like strains show high biochemical similarity. They reported that Rapid ID 32A test did not offer proper identification, because $\alpha$ - $\beta$-glucosidase positive strains of $C$. botulinum were classified as C. sporogenes and API $20 \mathrm{~A}$ did not allow for the proper identification of the two species mentioned above (13).

Honey seems to be one of the food products most contaminated with C. botulinum. We observed $8.5 \%$ prevalence of $C$. botulinum in this matrix. This result correlated with reports from other authors. Nevas et al. (20) described contamination of 26\% (29/112) Danish samples by $C$. botulinum spores. The lowest level of contamination was detected in Swedish samples - 2\% (1/50) (19). In Japan, two reports have been prepared on C. botulinum occurrence and according to Nakano and Sakaguchi (18) the percentage of positive samples reached 31\% (11/36), whereas Nakano et al. (17) found the occurrence of this pathogen in $8.5 \%(4 / 48)$ of examined samples. In Turkey, Küplülü et al. (12) described that $C$. botulinum spores were detected in 
$12.5 \%$ of honey samples. Midura (15) reported the contamination of $10 \%(9 / 90)$ of examined samples in the USA. However, in Khazakhstan, Mustafina et al. (16) noticed the occurrence of $C$. botulinum only in $0.91 \%(1 / 120)$ of honey samples.

C. perfringens possesses characteristic metabolic and morphological features which enable easier detection than in the case of $C$. botulinum strains. The strains of this opportunistic pathogen are capable of fast and dynamic growth at $30^{\circ} \mathrm{C}$ in contrast to the other Clostridia (e.g. C. botulinum) (14). The number of examined samples with $C$. perfringens was significantly higher than those contaminated with C. botulinum.

The occurrence of $C$. perfringens in honey has been very rarely reported in literature. Tomassetti et al. (25) described the presence of this microorganism in $16.2 \%(6 / 37)$ of jar honey and in $11.3 \%(6 / 53)$ of comb honey obtained from 37 farms of Latium Region.

The exact number of infective number of Clostridium spores remains undetermined; however, even $1 \mathrm{cfu}$ of $C$. botulinum could cause botulism symptoms in infants (15). On the basis of the occurrence of $C$. botulinum spores in examined samples, we could suggest that risk assessment should be implemented, especially on the entire honey harvesting process.

Conflict of Interests Statement: The authors declare that there is no conflict of interests regarding the publication of this article.

Financial Disclosure Statement: This study was financed by statutory research funds from the Polish Ministry of Science and Higher Education assigned to the Department of Hygiene of Animal Feedingstuffs, National Veterinary Research Institute.

Animal Rights Statement: All experiments on animals were conducted in approved laboratory unit with the approval of the II Local Ethics Committee in Lublin (Poland).

\section{References}

1. Austin J.W.: Clostridium botulinum. In: Food microbiology: Fundamentals and frontiers. Edited by Beuchat L.R., Doyle M.P., Montville T.J. ASM Press, Washington, 2001, pp. 329-349.

2. Baums C.G., Schotte U., Amtsberg G., Goethe R.: Diagnostic multiplex PCR for toxin genotyping of Clostridium perfringens isolates. Vet Microbiol 2004, 100, 11-16.

3. Carter A.C., Peck M.W.: Genomes, neurotoxins and biology of Clostridium botulinum Group I and Group II. Res Microbiol 2015, 166, 303-317.

4. Cherington M.: Clinical spectrum of botulism. Muscle Nerve 1998, 21, 701-710.
5. De Medici D., Anniballi F., Wyatt G. M., Lindström M., Messelhäußer U., Aldus C.F., Delibato E., Korkeala H., Peck M.W., Fenicia L.: Multiplex PCR for detection of botulinum neurotoxin-producing Clostridia in clinical, food, and environmental samples. Appl Environ Microbiol 2009, 20, 6457-6461.

6. Dover N., Barash J.R., Hill K.K., Xie G., Arnon S.S.: Molecular characterization of a novel botulinum neurotoxin type $\mathrm{H}$ gene. J Infect Dis 2014, 209, 192-202.

7. Grass J.E., Gould L.H., Mahon B.E.: Epidemiology of foodborne disease outbreaks caused by Clostridium perfringens, United States, 1998-2010. Foodborne Pathog Dis 2013, 10, 131-136.

8. Grenda T., Kukier E., Sieradzki Z., Goldsztejn M., Kwiatek K.: Molecular diversity of Clostridium botulinum and phenotypically similar strains. Pol J Vet Sci 2016, 4, 831-840.

9. Hatheway, C.L.: Toxigenic Clostridia. Clin Microbiol Rev 1990, 3, 66-98.

10. Hatheway, C.L.: Botulism: the present status of the disease. Curr Top Microbiol 1995, 195, 55-75.

11. Kizerwetter-Świda M., Binek M.: Clostridium botulinum toxicosis - still a serious problem. Post Mikrobiol 2009, 40, 2, 75-85.

12. Küplülü Ö., Göncüoğlü M., Özdemir H., Koluman A.: Incidence of Clostridium botulinum spores in honey in Turkey. Food Control 2006, 17, 222-224.

13. Lindström M., Jankola H.M., Hyytia E.K., Korkeala H.J.: Identification of Clostridium botulinum with API 20 A, Rapid ID 32 A and RapID ANA II. FEMS Immunol Med Microbiol 1999, 24, 267-274

14. Lindström M., Korkeala H.: Laboratory diagnostics of botulism. Clin Microbiol Rev 2006, 19, 298-314.

15. Midura T.F.: Update: infant botulism. Clin Microbiol Rev 1996, 9, 119-125.

16. Mustafina R., Maikanov B., Wiśniewski J., Tracz M., Anusz K., Grenda T., Kukier E., Goldsztejn M., Kwiatek K.: Contamination of honey produced in the Republic of Kazakhstan with Clostridium botulinum. Bull Vet Inst Pulawy 2015, 59, 241-246.

17. Nakano H., Okabe T., Hashimoto H., Sakaguchi G.: Incidence of Clostridium botulinum in honey of various origins, Jpn J Med Sci Biol 1990, 43, 183-195.

18. Nakano H., Sakaguchi G.: An unusually heavy contamination of honey products by Clostridium botulinum type $\mathrm{F}$ and Bacillus alvei. FEMS Microbiol Lett 1991, 63, 171-177.

19. Nevas M.: Clostridium botulinum in honey production with respect to infant botulism. Academic dissertation. Faculty of Veterinary Medicine. University of Helsinki, Helsinki 2006.

20. Nevas M., Lindström M., Hautamäki K., Puoskari S., Korkeala H.: Prevalence and diversity of Clostridium botulinum types A, B, E and $\mathrm{F}$ in honey produced in the Nordic countries. Int $\mathrm{J}$ Food Microbiol 2005, 105, 145-151.

21. Polish Standard: Animal feeding stuffs - Requirements and microbiological examinations. PN - R - 64791:1994.

22. Raphael B.H., Andreadis J.D.: Real-time PCR detection of the nontoxic non-hemagglutinin gene as a rapid screening method for bacterial isolates harboring the botulinum neurotoxin (A-G) gene complex. J Microbiol Meth 2007, 71, 343-346.

23. Samul D., Worsztynowicz P., Leja K., Grajek W.: Beneficial and harmful roles of bacteria from the Clostridium genus. Acta Biochim Pol 2013, 60, 515-521.

24. Sharma S.K., Whiting R.C.: Methods for detection of Clostridium botulinum toxin in foods. J Food Prot 2005, 68, 1256-1263.

25. Tomassetti F., Milito M., Dell'Aira E., De Santis L., Migliore G., Formato G.: Microbiological comparison between honey in jar and honey in comb for human. Ital J Food Saf 2009, 3, 65-66. 